Ethics and Halothane

J. M. K. Spalding, F.R.C.P. . . . . . . . . 739

Price of Prostatectomy

R. S. Murley, F.R.C.s.; P. F. J. Hickinbotham,

F.R.C.s. . . . . . . . . . . . . . . . . .739

Diet and Coronary Heart Disease

R. W. D. Turner, F.R.C.P., and K. P. Ball,

F.R.C.P. . . . . . . . . . . . . . . .740

Fibreoptic Bronchoscopy

S. W. Clarke, F.R.C.P. . . . . . . . . . 740

Reporting Deaths to the Coroner

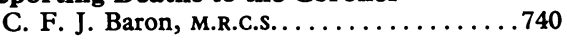

Escherichia coli 0148 and Diarrhoea in

Adults

B. Rowe, м.в., D.т.м.\&H. . . . . . . .741

Tetracycline-resistant Group A Strepto-

cocci

R. J. Fallon, M.D.............741
Trasylol for Pancreatitis

M. L. Lewis, M.R.C.PATH..........741

Alpha-fetoprotein in Amniotic Fluid in Early Normal Pregnancy and Intrauterine Fetal Death

L. Wiśniewski, M.D., and others. . . . . . .742

Prazosin in Patients with Chronic Renal Failure

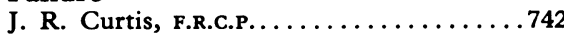

Hernias in Children

R. T. Burkitt, F.R.C.s.

Age Dependence of $T$-cells

N. Matsaniotis, M.D., and others. . . . . . 743

Saudi Arabian Medical School

R. A. Johnson, M.B........ . . . 743

Women in Medicine

Una M. P. Kroll, M.R.c.G.P...........743
G.M.C. By-election

J. G. Sowerbutts, F.R.C.P.ED. . . . . . . . 744

Perks for Practitioners

A. Jackson, M.B...............744

Trade Union Tactics

P. H. Woodcock, M.B.; P. E. Baldry, F.R.C.P. 744 Hospital Medical Staffing

G. I. B. Da Costa, F.R.C.S.ED. . . . . . . . . 744

Private Practice and the N.H.S.

H. C. Faulkner, M.R.C.G.P. . . . . . . . 745

New N.H.S. Management

M. Goldman, D.M.R.D..............745

Doctors' Pay

K. W. Beetham, M.B., D.M.R.T... . . . . . 745

Increased Mileage Allowances

J. Richardson .................745

N.H.S. Contraceptive Services

Norma H. Smith, M.B..............745
SIR,-Your leading article (7 September, p. 589) makes it clear that many responsible and informed doctors believe in an association between repeated exposure to halothane and liver damage; that death has occurred Irom liver damage after halothane; and that an anaesthetist who gives halothane to a patient who has been exposed to it in the previous four weeks might be held to be negligent. In short, you demonstrate that it is widely believed that repeated exposure to halothane may not be safe. You then, in effect, invite hospital ethics committees to approve investigations which include such repeated exposure.

One of the duties of an ethics committee

\section{Price of Prostatectomy}

SIR,-Under this title you publish an article (24 August, p. 511) by distinguished urologists in London, Livenpool, and Portsmouth. I hope that it will not seem irreverent for a general surgeon to examine their claims.

Firstly, it is said that wider use of transurethral prostatic resection could result in substantial savings of hospital capital and revenue costs. This is based upon evidence of a shorter mean stay in hospital: at the London Hospital, in round figures, roughly eight compared with 16 days for open operation, at Liverpool 10 compared with 19 , and at Portsmouth eight compared with 14 days. The authors indicate that the mean stay at the London includes "time wasted prior to operation." But cold cases are presumably admitted the day before operation and those with acute retention oould be investigated within a few days, which should surely not be described as time wasted. Any delays in referring patients from other units, however regrettable, are unrelated to the method of operation and therefore irrelevant. Would it not be better then to oompare the times spent in hospital after operation? The medical records of patients operated upon at one hospital by my current surgical registrar (a highly competent young man of 30 who has not required "prolonged and specialized training") show that the mean postoperative stay in the last two years was nine days. These operations are usually done transvesically with closure of the bladder. The urethral catheter is out after two days and the subcuticular sutures on the fifth day. We could, and oocasionally do, send patients home by the seventh day, but we generally keep them a little longer if not under pressure from emergency cases. Complications can occur after any form of surgery and there is certainly no virtue in being obsessed with the idea of unusually early discharge from hospital.

Secondly, it is claimed that "the waiting list moves twice as fast if transurethral resection is available." I know that I am not unique in having had no conventional "waiting list" for many years. All patients are admitted on a firm date from a unit diary and without delay. That being so I cannot say that $I$ am influenced in favour of an operation which the authors admit "demands prolonged and specialized training."

Thirdly, if there is to be a highly specialized urological service in all general hospitals the budgetary implications are by no means so simple as is claimed. A singlehanded urologist in a district hospital who did all the urology would leave no consultant cover during six weeks or so of annual leave; and if his general surgical colleagues provided no urological cover it would not be long before a second urologist was needed. Then, if not sooner, a special registrar would be required as well as resident staff. The secondary effects upon emergency cover, clinic and operating times, and reallocation of residents' duties would be considerable and need not be detailed here.

Fourthly, the authors seem naive in their contention that a hospital serving a population of 300,000 would need 15 prostatectomy beds in "today's conditions" but only 10 such beds if $80 \%$ of the operations were transurethral. Even were one prepared to accept these figures at their face value, it is surely common experience that establishing specialist units tends to increase and not decrease the overall work load.

Fifthly, as a general surgeon I shall not criticize the claim that "there are no increased risks of incontinence, stricture, or 
the need for further operation." I do know that not all urologists are so confident. Incidentally, my registrar has recently done open prostatectomy on a man who had transurethral resection by a distinguished London urologist only a few years ago.

I am in favour of increasing the number of specialist urological units in appropriate big hospitals. But in a majority of smaller district hospitals it would surely be wiser to aim at having no more than one surgeon skilled in endoscopic operations. Whether that surgeon need be a pure urologist is an open question, dependent upon the attitude of the individual concerned as well as the practice and aptitudes of his colleagues.-I am, etc.,

London $\mathbf{W} .1$

REGINALD S. MURLEY

SIR,-Mr. S. Agyrou and his colleagues (24 August, p. 51.1) show what a lot of money could be saved if most prostates were removed by transurethral resection rather than open operation. They are clearly doing a bit of coat-trailing, not to say empirebuilding, and will be disappointed if no one rises-so here goes.

I remove about 150 prostates a year, about half by transurethral resection and half by no-catheter retropubic prostatectomy, ${ }^{1}$ and I want to make the case for intelligent selection of cases for one or other method rather than doing them all the same way. In assessing the "best buy" for the N.H.S. Mr Agyrou and his colleagues rely on certain tendentious statements in their first paragraph which imply that it is proved that the two operations are equal in functional results and complication rates. Certain papers have appeared to show this, but it is far from proved and a follow-up for 10 years is necessary to assess the late incidence of recurrent obstruction, stone, and stricture. But there are more important considerations.

(1) It has been shown by Hutch and $\mathrm{Rambo}^{2}$ that the plane of finger enucleation lies between the adenoma on the inside and the circular unstripped urethral muscle fibres on the outside and that this plane is cleare in the large prostates. It is these muscle fibres on which we rely for postoperative continence. This plane is followed by a finger as easily as is the plane between a tangerine orange and its peel. It is not a plane seen on transurethral resection-the muscle fibres are not distinguishable from capsular fibres.

(2) It is impressive to see continence regained within hours of open removal of a large prostate, whereas in my experience this process often takes several days following transurethral resection.

(3) By resection I remove about $1 \mathrm{~g}$ of tissue per minute, which would mean a twohour operation for a $120 \mathrm{-g}$ gland. Enucleation takes perhaps one minute and the whole operation 30-40 minutes. I believe the postoperative complications-notably thromboses -would necessarily be commoner in the former case.

To sum up, I suggest that for large prostates much better results are obtained by open operation and for small ones by transurethral resection. Why a patient should stay in hospital after an open prostatectomy until the wound is healed I do not know. We send patients with hernias home after a few days and I see no reason why we should not do the same with prostate cases- currently mine go home on the eighth day and I am grateful to Mr. Agyrou and his colleagues for making me think about this. I propose to reduce this to, say, six days in straightforward cases.-I am, etc.,

Leicester

Paul Hickinbotham 1 Hickinbothan, P., Turner, W. D., and Sarma,
K. P., Journal of Urology, 1967, 97, 899.
2 Hutch, J. A., and Rambo, O. N., fournal of
Urology, 1970, 104, 443.

\section{Diet and Coronary Heart Disease}

SIR,-Many will share the reservations of your leading article (6 July, p. 4) on the report of the Advisory Panel of the Committee on Medical Aspects of Food Policy. ${ }^{12}$ The report aimed to reach "(1) organizations and individuals responsible for guidance of the public in relation to health and diet; (2) doctors who need to give advice to patients, and (3) scientific advisers of food manufacturers." It is therefore of great interest to many in the health professions and in industry.

Few will disagree with the committee's recommendations to avoid and treat obesity at all ages. Likewise there would be little dispute over its conclusion that the national consumption of saturated fats and sugar should be reduced. Where we strongly disagree with the report is in its inability to recommend an increase in the intake of polyunsaturated fats in the national diet. At least 11 other national and international committees have examined the same evidence and with one exception have made much stronger proposals. Moreover this committee of the Department of Health and Social Security has not given its reasons for differing from the other expert bodies.

The recommendation to reduce the amount of saturated fat in the diet from its present high level begs the question of what should take its place. A low-fat diet is unpalatable, and substitution of saturated by polyunsaturated fat makes eating far pleasanter, but in addition further lowers serum lipids. Most of the expert committees recommend an increase of polyunsaturated fats for the general population, with a polyunsaturated to saturated fat ratio of about 1.0 and a reduction of daily cholesterol intake to about $300 \mathrm{mg}$. Most also agree that sugar should be reduced in western diets, especially for the control of obesity, even though none seem to accept Professor J. Yudkin's view that sugar is more important than fat as a cause of coronary heart disease. It might be added that for some people a reduction of alcohol is also important on account of its calorie content and contribution to hypertriglyceridaemia. We also agree with you in regretting that the parel did no recommend any moderation of salt intake.

In our opinion the food industry should not be deterred in its efforts to assist reasonable dietary recommendations but rather be encouraged to develop and market suitable alternatives. Unless foods are labelled with their fat content, as advised by nine of the other 11 expert committees, and alternative meals are readily available in catering establishments, members of the public will not even be able to make their own choice in the matter. We note that members of the committee were not always able to reach agreed condusions, suggesting that there was an unsatisfactory compromise on several issues.

Further conclusive evidence leading to proof on the question of diet and coronary heart disease is most unlikely to come within the next 10 years, if at all. In the United States it was calculated that a dietary trial large enough to produce a conclusive answer, would have cost in 1969 between $\$ 250 \mathrm{~m}$. and $\$ 500 \mathrm{~m}$., and hence it was not carried out. Doctors must advise their patients on this question, as they do on many other matters, without proof and on the balance of the probabilities. We believe there is enough evidence for them to advise their patients, particularly those with other risk factors, on the lines suggested above.

Unfortunately this report will have done little to encourage people to make an effective alteration in their eating habits or the food industry to help them to do so. We hope that the Government will consider views other than those of this committee before deciding on important food policies. -We are, etc.,

Central Middlesex Hospital,

KeIth P. BALL London N.W.10

Western General Hospital,

RICHARD TURNER

Edinburgh

\section{Department of Health and Social Security, Diet Subjects 7. London, H.M.S.O., 1974} 2 Darke, S., Health Trends, 1974, 6, 42.

\section{Fibreoptic Bronchoscopy}

SIR,-May I comment on two of your recent leading articles, "The Fibreoptic Revolution" (20 July, p. 131) and "Safety and Fibreoptic Bronchoscopy" (31 August, p. 542)? In the first you state that "trans" nasal bronchoscopy can be performed as an outpatient procedure without sedation." In the second you state that "local anaesthesia can cause major complications and should be used cautiously; it may in fact be unnecessary for the majority of patients if the transnasal route is used."

On the basis of personal experience with over 100 transnasal, fibreoptic bronchoscopies with local anaesthesia (lignocaine) and sedation and personal appraisal of others' techniques I believe both the above comments to be quite misleading. Without sedation fibreoptic bronchoscopy is difficult because of gagging, coughing, and anxiety, particularly in outpatients. Without local anaesthesia it is extremely difficult to pass the larynx - I have tried, inadvertently, and failed. Taken together, the two comments suggest that fibreoptic bronchoscopy can be performed easily without either sedation or local anaesthesia. Anyone who has tried will know that this is not the case. Furthermore, I have had no complications using bath.

The technique is safe and the procedure useful but not under the conditions suggested by your two leading articles.-I am, etc.,

Brompton Hospital

S. W. Clarke

London S.W.3

\section{Reporting Deaths to the Coroner}

SIR,-Dr. J. D. J. Havard (31 August, p. 576) refers only to the opinion of counsel which he selects and not to the opinion of counsel given to the B.M.A. in the opposite 